This is the author's final, peer-reviewed manuscript as accepted for publication. The publisher-formatted version may be available through the publisher's web site or your institution's library.

\title{
Production of methyl ethyl ketone from biomass using a hybrid biochemical/catalytic approach
}

Alisha Multer, Nathan McGraw, Keith Hohn, and Praveen Vadlani

\section{How to cite this manuscript}

If you make reference to this version of the manuscript, use the following information:

Multer, A., McGraw, N., Hohn, K., \& Vadlani, P. (2013). Production of methyl ethyl ketone from biomass using a hybrid biochemical/catalytic approach. Retrieved from http://krex.ksu.edu

\section{Published Version Information}

Citation: Multer, A., McGraw, N., Hohn, K., \& Vadlani, P. (2013). Production of methyl ethyl ketone from biomass using a hybrid biochemical/catalytic approach. Industrial \& Engineering Chemistry Research, 52(1), 56-60.

Copyright: @ 2012 American Chemical Society

Digital Object Identifier (DOI): doi:10.1021/ie3007598

Publisher's Link: http://pubs.acs.org/doi/full/10.1021/ie3007598

This item was retrieved from the K-State Research Exchange (K-REx), the institutional repository of Kansas State University. K-REx is available at http://krex.ksu.edu 


\title{
Production of methyl ethyl ketone from biomass using a hybrid biochemical/catalytic approach
}

\author{
Alisha Multer ${ }^{1}$, Nathan McGraw ${ }^{2}$, Keith Hohn², and Praveen Vadlani ${ }^{2}$ \\ (1) St. Edward's University, Austin, TX 78704 (2) Kansas State University, \\ Manhattan, KS 66506
}

\begin{abstract}
The recent demand for sustainable routes to fuels and chemicals has led to an increased amount of research in conversion of natural resources. A potential approach for conversion of biomass to fuels and chemicals is to combine biochemical and chemical processes. This research used microbial fermentation to produce 2,3-butanediol, which was then converted to methyl ethyl ketone by dehydration over a solid acid catalyst. The fermentation process was performed using the bacteria Klebsiella oxytoca (K.O). 2,3butanediol then dehydrated to form methyl ethyl ketone on a solid acid catalyst, the proton form of ZSM-5, and heat. The goal was to determine the reaction kinetics of 2,3butanediol dehydration over ZSM-5, and to demonstrate the hybrid biochemical/thermochemical approach for synthesizing chemicals from biomass. It was found that ZSM-5 produced methyl ethyl ketone with high selectivity (greater than $90 \%$ ), and could convert fermentative 2,3-butanediol to methyl ethyl ketone. The reaction order of 2,3-butanediol dehydration was found to be slightly large than one, and an activation energy of $32.3 \mathrm{~kJ} / \mathrm{mol}$ was measured.
\end{abstract}

\section{Introduction}

The recent demand for sustainable routes to fuels and chemicals has led to an increased amount of research in conversion of natural resources. Fermentation can convert biomass to a wide variety of products, frequently with high selectivity ${ }^{1}$. However, the reaction rates are generally slow, and products are general highly dilute. Inorganic catalytic routes offer higher reaction rates because higher temperatures can be used; however, product selectivity can be an issue.

One potential approach for conversion of biomass to fuels and chemicals is to combine biochemical and thermochemical/catalytic processes. With this approach, a process can combine a fermentation route that gives high selectivity and productivity to a specific product with an inorganic catalytic process to further upgrade this product. In this contribution, the hybrid approach is applied to the synthesis of methyl ethyl ketone (MEK) from biomass-derived carbohydrates. This process was chosen because methyl ethyl ketone is a valuable chemical, with extensive use as a solvent and in painting and coatings, because fermentation can produce high concentrations of 2,3-butanediol (2,3$\mathrm{BD}$ ), and because dehydration of 2,3-BD to MEK can be achieved with high selectivity over acid catalysts.

2,3-BD production is an attractive microbial fermentation because it can produce 2,3-BD at a high concentration,3. Several bacterial species are known to produce 2,3-BD from pyruvate. Jansen et al. ${ }^{4}$ obtained a butanediol concentration of $12.63 \mathrm{~g} / \mathrm{l}$ by fermentation of media containing $50 \mathrm{~g} / \mathrm{l}$ of xylose in a $7-\mathrm{L}$ batch fermentor using $\mathrm{K}$. oxytoca ATCC 
8724. A maximum butanediol productivity of $1.35 \mathrm{~g} / \mathrm{l} / \mathrm{h}$ was obtained with an initial xylose concentration of $100 \mathrm{~g} / \mathrm{l}$, when different xylose concentrations varying from 5-150 $\mathrm{g} / \mathrm{l}$ were used. Qureshi and Cheryan ${ }^{5}$ obtained a butanediol yield of $0.5 \mathrm{~g} / \mathrm{g}$ of glucose with a maximum butanediol concentration of $84.2 \mathrm{~g} / 1$ using K. oxytoca ATCC 8724. In two- step fed batch fermentation the concentration of butanediol obtained was $85.5 \mathrm{~g} / \mathrm{l}^{6}$ obtained a final butanediol concentration of $95.5 \mathrm{~g} / 1$ with a yield and productivity of 0.48 $\mathrm{g} / \mathrm{g}$ of glucose and $1.71 \mathrm{~g} / \mathrm{l} / \mathrm{h}$ using K. oxytoca ME-UD-3 using a two stage agitation speed control strategy under batch fermentation conditions. 2,3-BD synthesis occurs in the late $\log$ phase/stationary phase of fermentation ${ }^{3}$.

2,3-BD produced via microbial fermentation can be further be converted to MEK by dehydration over an acid catalyst. Such a hybrid approach has been suggested earlier, for example by Tran and Chambers ${ }^{7}$. Tran and Chambers studied the dehydration of fermentative 2,3-BD over sulfonic acid-containing alumina and silica-alumina catalysts. These researchers reported high conversion and selectivity, but noted catalyst deactivation that they attributed to loss of sulfonic acid groups. Emerson and coworkers studied dehydration 2,3-BD to MEK using sulfuric acid and used fermentation broth in a limited number of experiments ${ }^{8}$. They reported that MEK was produced from fermentation broth, but measured a slower reaction rate. This paper further describes the reaction kinetics of 2,3-BD dehydration, measuring first-order kinetics in 2,3-BD. Bucsi et al. studied the dehydration of diols, including 2,3-BD, over Nafion and NaHX zeolites with the primary goal of understanding reaction pathways for producing different products ${ }^{9}$. Torok and coworkers studied the catalytic dehydration of 2,3-BD and other diols over heteropolyacids ${ }^{10}$.

While these previous studies provide some information on 2,3-BD dehydration, they are generally lacking in detailed reaction kinetics, particularly for solid acid catalysts. In addition, only a limited number of solid acid catalysts have been studied, some of which were not found to be stable. This paper seeks to extend the body of knowledge on a hybrid fermentation/catalytic approach for producing MEK from biomass. Towards this goal, fermentation using Klebsiella oxytoca (K.O) is used to convert sugars to 2,3butanediol(2,3-BD). 2,3-BD is then catalytically dehydrated over a solid acid catalyst (the proton form of ZSM-5, HZSM-5). The reaction kinetics of 2,3-BD on HZSM-5 are measured, and the activity of HZSM-5 for dehydration of 2,3-BD found in fermentation broth is measured.

\section{Experimental}

\section{Preparation of 2,3-BD by Fermentation}

Experiments were performed using synthetic glucose for the production of 2,3 $\mathrm{BD}$ in a $7 \mathrm{~L}$ fermentor. $3500 \mathrm{ml}$ fermentation medium was charged into the vessel and the whole vessel (including $\mathrm{pH}$ and DO probes) was sterilized at $1210^{\circ} \mathrm{C}$ for 30 minutes. A $1000 \mathrm{ml}$ glucose solution was sterilized separately and the concentration was adjusted to to give $5 \%(\mathrm{w} / \mathrm{v})$ in the fermentor. Klebsiella oxytoca (ATCC\# 8724) was inoculated in $500 \mathrm{ml}$ growth media consisting of $10 \mathrm{~g} \mathrm{~L}-1$ peptone, $5 \mathrm{~g} \mathrm{~L}-1$ sodium chloride, and $3 \mathrm{~g} \mathrm{~L}-1$ beef extract. Inoculum was incubated at $37^{\circ} \mathrm{C}$ and agitated at $130 \mathrm{rpm}$ for 24 hours. The 3.5 
liters fermentation media consisted of $2 \mathrm{~g} \mathrm{~L}-1 \mathrm{KH} 2 \mathrm{PO} 4,13.7 \mathrm{~g} \mathrm{~L}-1 \mathrm{~K} 2 \mathrm{HPO} 4,3.3 \mathrm{~g} \mathrm{~L}-1$ (NH4)2HPO4, $6.6 \mathrm{~g} \mathrm{~L}-1$ (NH4)2SO4, $0.25 \mathrm{~g} \mathrm{~L}-1 \mathrm{MgSO} 4 \cdot 7 \mathrm{H} 2 \mathrm{O}, 0.05 \mathrm{~g} \mathrm{~L}-1 \mathrm{FeSO} 4 \cdot$ $7 \mathrm{H} 2 \mathrm{O}, 0.001 \mathrm{~g} \mathrm{~L}-1 \mathrm{ZnSO} 4 \cdot 7 \mathrm{H} 2 \mathrm{O}, 0.001 \mathrm{~g} \mathrm{~L}-1 \mathrm{MnSO} 4 \cdot \mathrm{H} 2 \mathrm{O}, 0.01 \mathrm{CaCl} 2 \cdot 2 \mathrm{H} 2 \mathrm{O}$, $0.05 \mathrm{~g} \mathrm{~L}-1$ EDTA. After sterilization, the vessel was cooled, the glucose solution and 500 $\mathrm{ml}$ inoculum were added, and the fermentation was initiated. Concentrated sodium hydroxide (3 molar) was used to maintain $\mathrm{pH}$ around 5.2-5.3. Samples were collected at scheduled intervals and batch was run for 37 hours. Dry weight data were collected by centrifuging $10 \mathrm{ml}$ samples and collecting pellets. Pellets were then dried at $80{ }^{\circ} \mathrm{C}$ and weighed.

Concentrations of sugars and butanediol in the fermentation broth were estimated using HPLC with RID detector and phenomenex monosaccharide column. Degassed MilliQ water was used as the mobile phase with a flow rate at $0.6 \mathrm{ml} / \mathrm{min}$. The column and RID temperatures were set at $83^{\circ} \mathrm{C}$ and $60^{\circ} \mathrm{C}$, respectively. Samples were diluted $1: 1$ with deionized water and passed through a filter before analysis. Samples were measured against standards for glucose and 2,3-butanediol.

Some fermentation samples were used as the feed for 2,3-BD dehydration. The broth was centrifuged to separate the solid and liquid phases prior to feeding it over the solid acid catalyst.

\section{2,3-BD conversion to MEK}

Reaction kinetics of the dehydration of 2,3-butanediol to methyl ethyl ketone of HSZM-5 were measured in a packed bed reactor. A schematic of the reactor is shown in Figure 1. An aqueous solution of 2,3-BD were pumped to the reactor using a Valco Series M liquid-handling pump. The reactant was fed to a steel reactor where the catalysts (proton form of ZSM-5, HZSM-5) was held in place by quartz wool on top of a wire mesh. The reactor was heated with a furnace that surrounds the steel reactor. Products from the reactor exited the reactor and flowed to a three-way valve. This valve directed products either to a sample vial or to a collection flask for waste.

Prior to reaction, the catalyst was heated in a stream of nitrogen (introduced by a threeway valve) to the reaction temperature. Samples were drawn twenty minutes after the 2,3-BD solution was introduced, which was found to be sufficient time to achieve steady state. Three samples were collected for each condition studied.

Samples were diluted with ethanol(one milliliter of ethanol to three milliliters of sample), which serves as initial standard, prior to injection into an SRI 8610 gc. 2,3-BD, MEK, and the only side product (2-methylpropanal) were separated on a Chromosorb 101 column using a following temperature program was used: the staring temperature was $100^{\circ} \mathrm{C}$, and temperature was ramped by $40^{\circ} \mathrm{C}$ per minute to $190^{\circ} \mathrm{C}$, and then was ramped by $10^{\circ} \mathrm{C}$ per minute to $230^{\circ} \mathrm{C}$ where temperature was held for five minutes. 


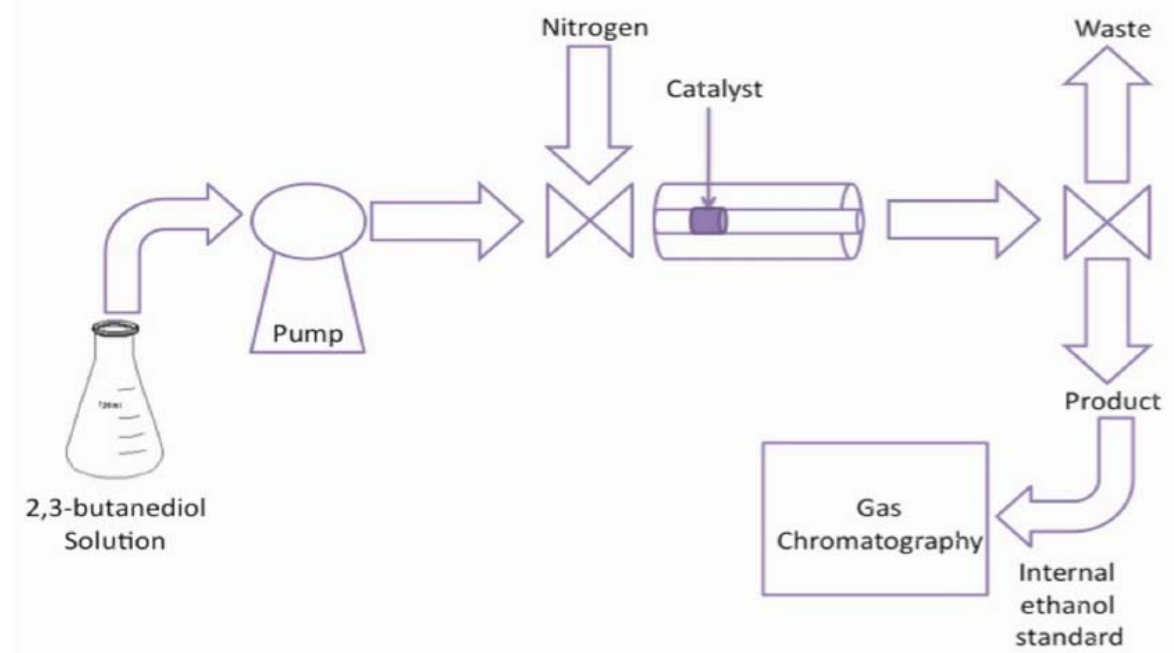

Figure 1. Schematic of packed bed reactor used to measure reaction kinetics of 2,3butanediol dehydration to methyl ethyl ketone on HZSM-5.

To measure reaction kinetics, the concentration of 2,3-BD in the feed, the reaction temperature, and the total molar flow rate were varied. Conversion of 2,3-BD was measured for three different concentrations of 2,3-BD $(30 \mathrm{~g} / \mathrm{L}, 50 \mathrm{~g} / \mathrm{L}$ and $80 \mathrm{~g} / \mathrm{L})$ and three different flow rates $(90 \mathrm{ml} / \mathrm{hr}, 110 \mathrm{ml} / \mathrm{hr}$, and $130 \mathrm{ml} / \mathrm{hr})$ at $200^{\circ} \mathrm{C}$ to determine the reaction rate and estimate reaction order In addition, the reactor was run with an inlet concentration of $50 \mathrm{~g} / \mathrm{L}$ at three different temperatures $\left(175^{\circ} \mathrm{C}, 200^{\circ} \mathrm{C}\right.$ and $\left.225^{\circ} \mathrm{C}\right)$.

Prior to running kinetic trials, the temperature was held constant at $200^{\circ} \mathrm{C}$ while the total flow rate was increased to determine whether external mass transfer limitations were important. It was found that the conversion increased as flow rate was increased up to a volumetric flowrate of $70 \mathrm{ml} / \mathrm{hr}$. Because the catalyst mass was being held constant, this indicated that external mass transfer limitations were important at flow rates below 70 $\mathrm{ml} / \mathrm{hr}$. Beyond $70 \mathrm{ml} / \mathrm{hr}$, conversion decreased with increasing flow rate, the expected trend. For this reason, all experiments were run at flow rates greater than $70 \mathrm{ml} / \mathrm{hr}$.

HZSM-5 was pelletized prior to loading into the reactor. Catalyst powder was placed into a Carver press and pressed into a pellet. The pellet was then broken and sieved to give $\sim 0.7 \mathrm{~mm}$ particles. Approximately 0.25 grams was placed in the reactor for each trial.

\section{Calculation of Conversion and Selectivity}

Conversion of 2,3-BD was calculated from the difference in the 2,3-BD molar flow rate entering the reactor and in the products: 
$X=\frac{F_{A o}-F_{A}}{F_{A o}}$

Two products were detected following 2,3-BD dehydration: methyl ethyl ketone and 2methyl propanal. The selectivity of MEK was calculated as the ratio of the molar flow rate of MEK divided by the total molar flow rate of products(methyl ethyl ketone and 2methylpropanal in our studies):

$S_{M E K}=\frac{F_{M E K}}{F_{M E K}+F_{p r o p}}$

\section{Data Analysis for Determining Reaction Kinetics}

The mole balance for a packed bed reactor is ${ }^{11}$ :

$F_{\text {Ao }} \frac{d X}{d W}=-r_{A}{ }^{\prime} F_{A 0}$

where: $\mathrm{F}_{\mathrm{A} 0}$ is the inlet molar flow of the reaction (species $\mathrm{A}$ ), $\mathrm{X}$ is the fractional conversion of $\mathrm{A}, \mathrm{W}$ is the catalyst weight, and $\mathrm{r}_{\mathrm{A}}$ ' is the reaction rate of species $\mathrm{A}$ per gram catalyst.

This can be rewritten as:

$\frac{d X}{d\left(W / F_{A o}\right)}=-r_{A}^{\prime}$

Equation 4 shows that the reaction rate in a packed be reactor can be estimated from the slope of $\mathrm{X}$ plotted as a function of $\mathrm{W} / \mathrm{F}_{\mathrm{Ao}}$. In our experiments, the inlet molar flow rate was varied for a fixed catalysts weight to change $\mathrm{W} / \mathrm{F}_{\mathrm{Ao}}$. The measured conversion was then plotted as a function of $\mathrm{W} / \mathrm{F}_{\text {Ao }}$ so that reaction rate could be estimated.

Reaction rate, $-\mathrm{r}_{\mathrm{A}}$, is a function of the concentration of $\mathrm{A}$ according to:

$-\mathrm{r}_{\mathrm{A}}=\mathrm{kC}_{\mathrm{A}}{ }^{\alpha}$

where: $\mathrm{k}$ is the reaction rate constant, $\mathrm{C}_{\mathrm{A}}$ is the concentration of species $\mathrm{A}$, and alpha is the order of the reaction.

The order of reaction was found using the differential method, where reaction rate was plotted versus $\mathrm{C}_{\mathrm{A}}$ on a $\log$-log plot. Data at three temperatures were fit with the Arrhenius equation to give the activation energy and pre-exponential for the reaction. 


\section{Results and Discussions}

\section{Fermentation to 2,3-Butanediol}

Figure 2 shows the profiles of glucose utilization, biomass (cell dry weight) and butanediol production with time. Based on the experiments performed at the $7 \mathrm{~L}$ fermentor level, we successfully repeated the results obtained at shake flask level (results not shown). 2,3-butanediol yield from total glucose consumed is about $0.63 \mathrm{~g} / \mathrm{g}$. Further, the initial batch fermentation was completed by 37 hours resulting in $1.1 \mathrm{~g} / \mathrm{l} / \mathrm{hr}$ productivity (whereas it took 48 hours to attain the same value in shake flask studies).

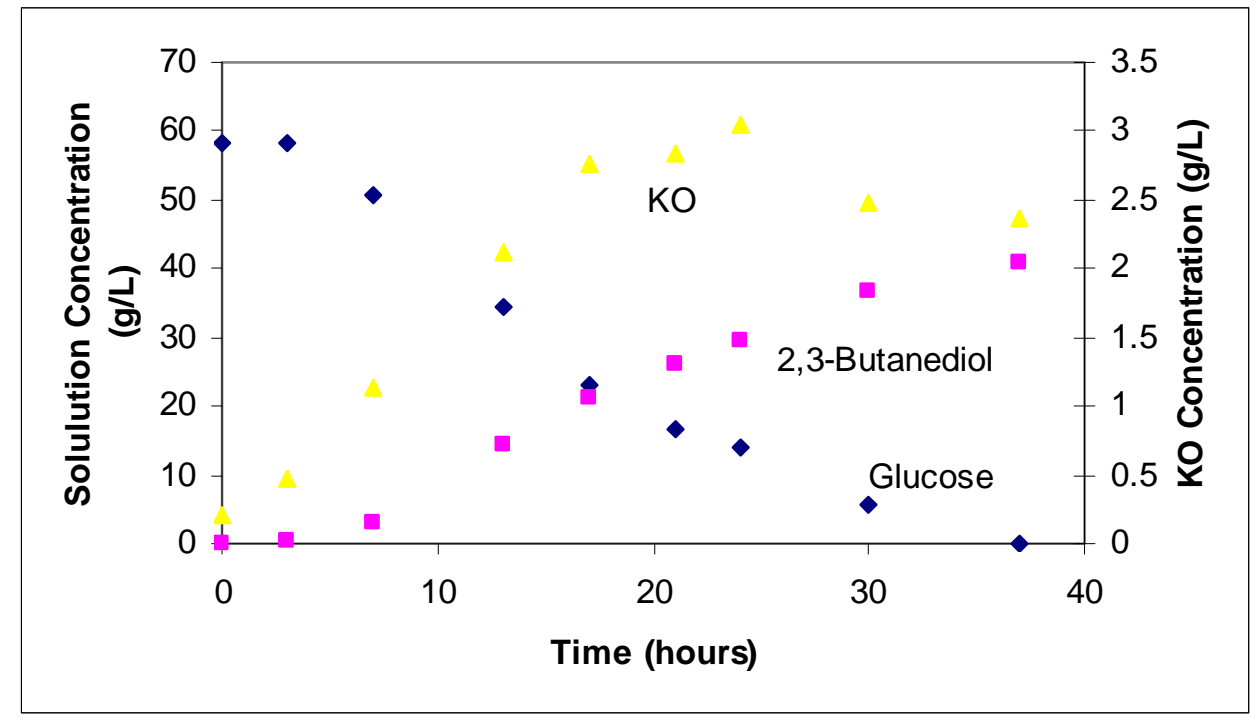

Figure 2. Fermentation profile of 2,3 butanediol synthesis using Klebsiella oxytoca

\section{2,3-Butanediol Dehydration Kinetics}

Figure 3 shows the measured conversion of $2,3-\mathrm{BD}$ as a function of $\mathrm{W} / \mathrm{F}_{\mathrm{Ao}}$ for three different inlet concentrations. As expected, all three sets of data show a linear trend, from which we can estimate reaction rate for the slope of the line. 


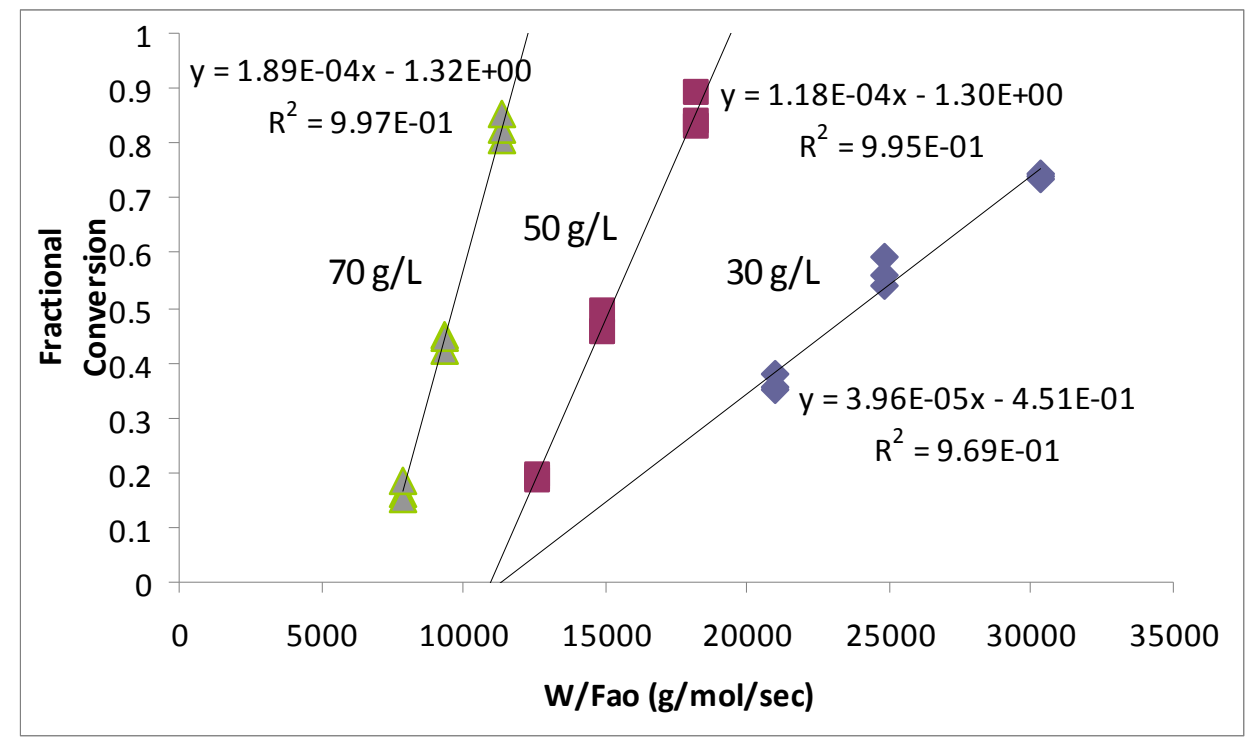

Figure 3. Reaction kinetics for 2,3-butanediol dehydration to methyl ethyl ketone. 2,3-butanediol is plotted as a function of the ratio of catalyst weight to inlet molar flow rate. The slope of each line gives the reaction rate.

The reaction order can be estimated by plotting reaction rate as a function of concentration on a log-log plot. Because the data were obtained under conditions that conversion was large, the concentration could not be assumed to be that of the inlet concentration. Instead, the concentration in the packed bed was changing. We estimated the concentration for each reaction rate from the conversion (i.e. $\mathrm{C}_{\mathrm{A}}=\mathrm{C}_{\mathrm{Ao}}(1-\mathrm{X})$ ) measured for the middle set of data points.

Figure 4 shows the log-log plot of reaction rate for different 2,3-BD concentrations. As seen in this plot, a linear trend is noted with a slope of 1.226. This indicates a reaction order of 1.226 . 


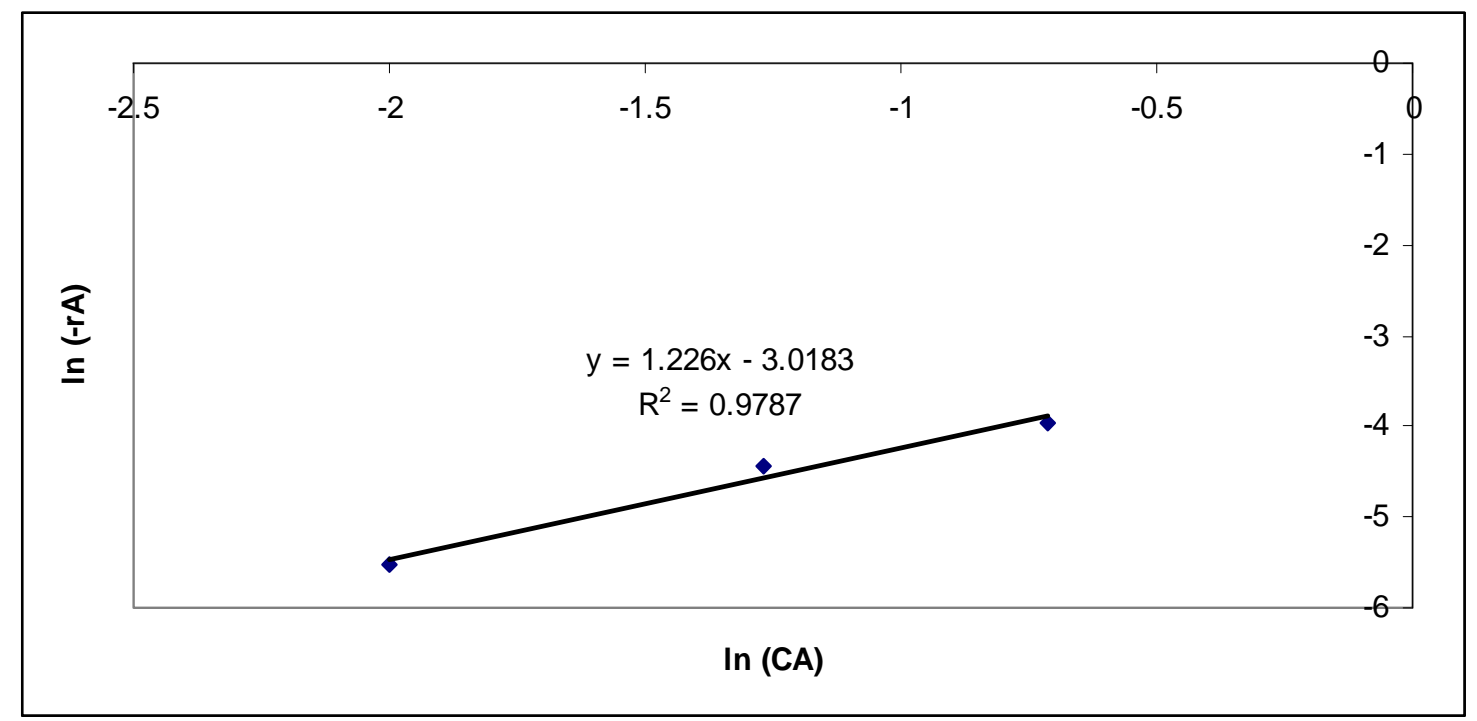

Figure 4. Log-log plot of reaction rate versus concentration of 2,3-butanediol. The slope of the line gives the reaction order.

To determine the Arrhenius constants, the reaction rate constant was calculated at three temperatures from the measure reaction rates by dividing reaction rate by $2,3-\mathrm{BD}$ concentration. In doing these, we assumed a first-order reaction, even though Figure 4 suggested a slightly higher reaction order. Figure 5 is an Arrhenius plot of the reaction rate constant for 2,3-BD dehydration. This plot shows a slope of -3889.4 , which corresponds to an activation energy of $32.34 \mathrm{~kJ} / \mathrm{mol}$. The pre-exponential was found to be $8.95 \mathrm{sec}^{-1}$.

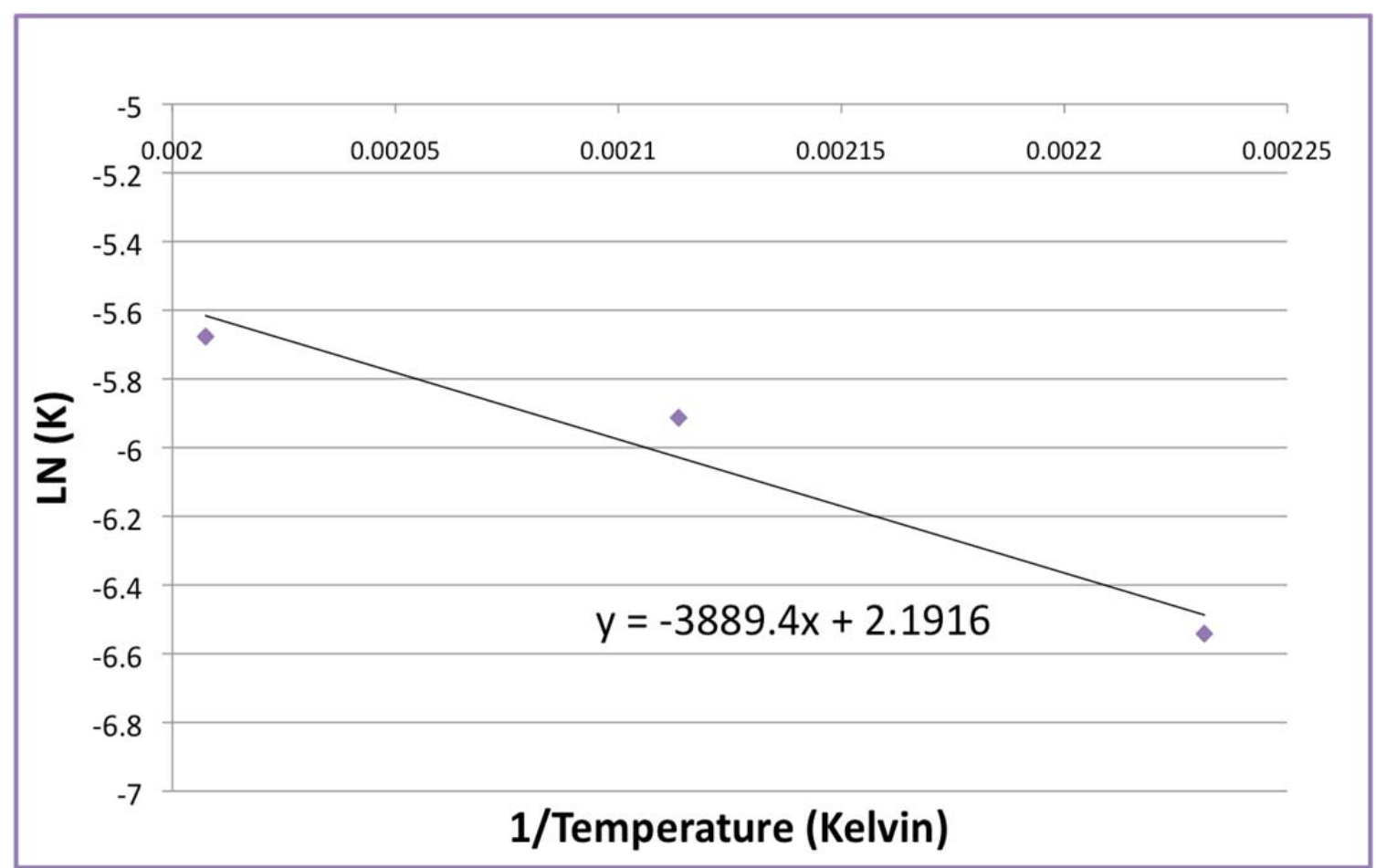

Figure 5. Arrhenius plot for 2,3-butanediol dehydration 


\section{Product Selectivity}

Methyl ethyl ketone was always the major product from 2,3-BD dehydration, with selectivity typically greater than $90 \%$. Selectivity was nearly constant for the conditions studied. Figure 6 shows the selectivity to MEK and 2-methylpropanal as a function of temperature. As seen in this figure, the selectivities are essentially unchanged as temperature is increased.

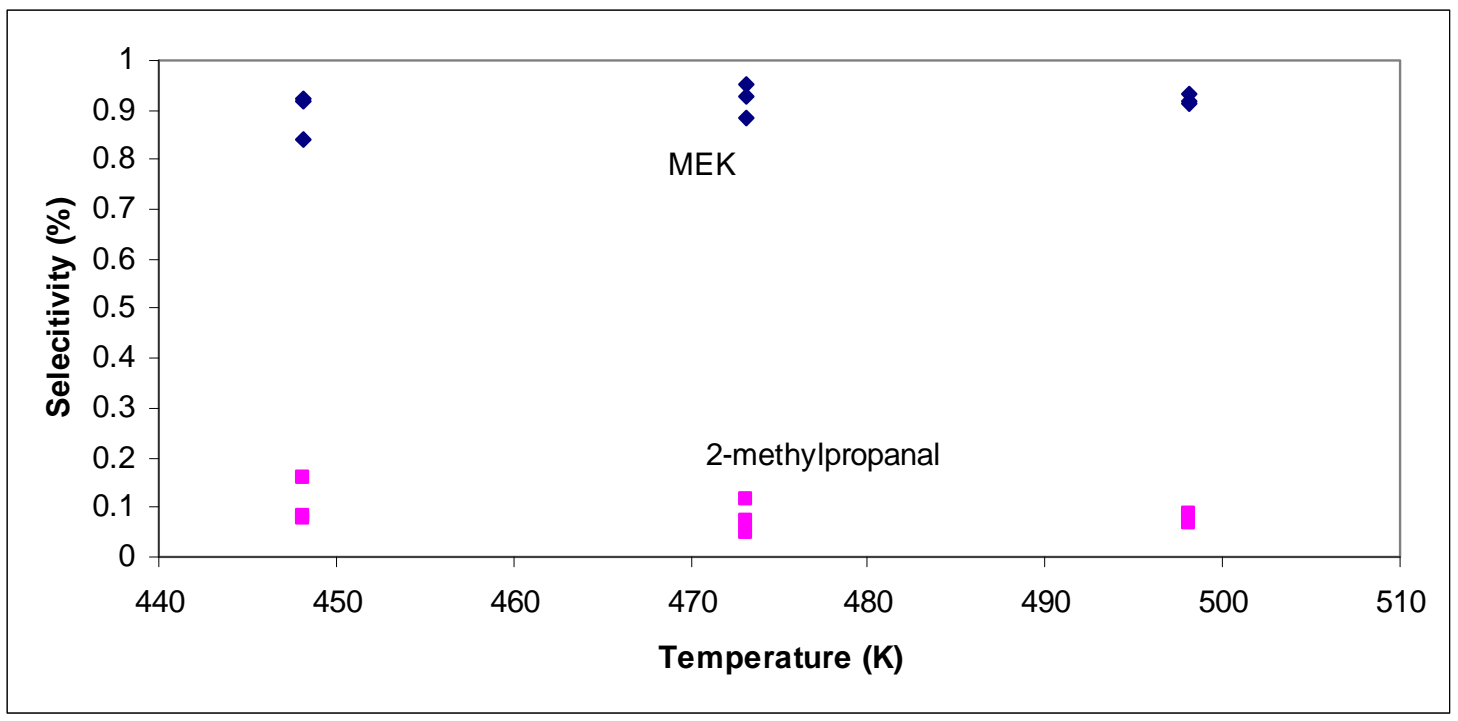

Figure 6. Selectivity in 2,3-butanediol dehydration as a function of temperature.

\section{Dehydration of 2,3-Butanediol Produced from Fermentation}

The activity of ZSM-5 for dehydration of fermentative 2,3-BD was tested by pumping fermentation broth through the catalyst bed. The concentration of the broth was estimated using the gas chromatograph to be consistent with the data analysis used to analyze the product. From this measure, the 2,3-BD concentration was only $2.63 \mathrm{~g} / \mathrm{L}$ $(0.03 \mathrm{~mol} / \mathrm{L})$. This was much lower than can generally be formed via fermentation (see Figure 2). This fermentation broth was sent through the reactor at $200^{\circ} \mathrm{C}$ at $130 \mathrm{~mL} / \mathrm{hr}$. A conversion of $13 \%$ was noted after operating the reactor for one hour.

The long-term stability of the catalytic process operating with fermentation-derived 2,3BD was not assessed. Catalyst deactivation has been described by others when fermentation broth is used ${ }^{7}$, so this deserves further study. We have found no evidence of catalyst deactivation using pure 2,3-BD streams over 40 hours.

\section{Comparison of Results to Literature}

Emerson and coworkers measured reaction kinetics for 2,3-BD dehydration with sulfuric $\operatorname{acid}^{8}$. They found that the reaction was first order in 2,3-BD. Neish and coworkers, on the other hand, reported that 2,3-BD dehydration was $2^{\text {nd }}$ order when run in the absence of water ${ }^{12}$. Our results found a reaction order slightly above 1, suggesting agreement 
with Emerson and coworkers. The activation energy measured in this paper (32.3 $\mathrm{kJ} / \mathrm{mol})$ was smaller than that reported by Emerson and coworkers $(150.7 \mathrm{~kJ} / \mathrm{mol})$, most likely due to difference between the heterogeneous catalyst used in this work and the homogeneous acid used in their study.

Selectivity to MEK was over $90 \%$ in this work, in agreement with that reported by Bucsi ${ }^{9}$ on supported heteropoly acids. Torok also reported high selectivity to MEK on Nafion and NaHX zeolite ${ }^{10}$, though they reported dioxolanes as important side products and reported MEK selectivities lower than we found(less than $80 \%$ ). Using sulfuric acid, Emerson reported MEK yields of over $90 \%$, where their yield is equivalent to selectivity in this paper. They suggested that aldol condensation limited MEK selectivity. These results suggest that HZSM-5 is as selective or more selective than other reported catalysts.

\section{Conclusions}

HZSM-5 is an active and selective catalyst for dehydration of 2,3-butanediol, and can be used to dehydrate 2,3-butanediol produced through fermentation. Over $90 \%$ selectivity to methyl ethyl ketone was produced on HZSM-5, with 2-methyl propanal as the only other product detected. Dehydration kinetics were found to depend on 2,3-butanediol concentration with a slightly higher reaction order than one (1.22). The activation energy was estimated to be $32.3 \mathrm{~kJ} / \mathrm{mol}$.

\section{Acknowledgements}

Support for Alisha Multer from an NSF REU site grant (NSF EEC\#0851799) is gratefully acknowledged.

\section{Dedication}

This submission is dedicated to L.T. Fan, Distinguished Professor of Chemical Engineering at Kansas State University. L.T.'s contributions in the field of biochemical and reaction engineering are an inspiration, and the authors feel fortunate to have had the opportunity to work with and learn from L.T.

\section{References}

1. Lee, J.W.; Kim, H.U.; Choi, S.; Yi, J.; Lee, S.Y.; Microbial production of building block chemicals and polymers. Curr. Opinion in Biotech. 2011, 22, 758.

2. Syu, M.J. Biological production of 2,3-butanediol. Appl. Microbiol. Biotechnol. 2001, 55, 10.

3. Celinska, E.; Grajek, W. Biotechnological production of 2,3-butanediol-Current state and prospects. Biotechnol. Adv. 2009, 27, 715.

4. Jansen, N.B.; Flickinger, M.C.; Tsao, G.T. Production of 2,3-Butanediol from DXylose by Klebsiella-Oxytoca Atcc 8724. Biotechnol. Bioeng. 1984, 26, 362.

5. Qureshi, N.; Cheryan, M. Effects of Aeration on 2,3-Butanediol Production from Glucose by Klebsiella-Oxytoca J. Ferment. Bioeng. 1989, 67, 415. 
6. Xiao, Z.; Ma, C.; Xu, P.; Lu, J.R. Acetoin Catabolism and Acetylbutanediol Formation by Bacillus pumilus in a Chemically Defined Medium. Plos One 2009 4, e5627.

7. Tran, A. V.; Chambers, R. P., The dehydration of fermentative 2,3-butanediol into methyl ethyl ketone. Biotechnol. Bioeng. 1987, 29, 343.

8. Emerson, R. R.; Flickinger, M. C.; Tsao, G. T., Kinetics of dehydration of aqueous 2,3-butanediol to methyl ethyl ketone. Ind. Eng. Chem. Prod. Res. Dev. 1982, 21, 473.

9. Bucsi, I.; Molnár, Á.; Bartók, M.; Olah, G., Transformation of 1,2-diols over perfluorinated resinsulfonic acids (nafion-H). Tetrahedron 1994, 50, 8195.

10. Torok, B.; Bucsi, I.; Beregszaszi, T.; Kaposci, I.; Molnar, A., Transformation of diols in the presence of heteropoly acids under homogeneous and heterogeneous conditions, J. Mol. Catal. A: Chem. 1996, 107, 305.

11. Fogler, H.S. Elements of Chemical Reaction Engineering, $4^{\text {th }}$ Edition; Prentice Hall: 2005.

12. Neish, A.C.; Haskell, V.C.; MacDonald, F.J. Production and Properties of 2,3Butanediol. 6. Dehydartion by Sulphuric Acid. Can. J. Res. 1945, 23B, 281. 